\title{
Social Media, Democracy and Public Service Media
}

\section{Petros Iosifidis, City University London, UK}

\section{Introduction}

The traditional Habermasian concept of the national public sphere created by the mass media of newspapers and television is said to have transformed to a multi-layered sphere of online and social networks which are increasingly important in engaging and mobilizing citizenship and in shaping the discourse within which rational discussion takes place. This article argues that the democratizing and empowering functions of the Internet and the new social media is being exaggerated and represent technological optimism for a number of reasons: the open participation of the Internet can turn chaotic; there is a problem of inclusiveness; censorship might be an issue; the Internet has become a major arena for corporate activity; the Internet's content is highly partisan; and above all, extensive dialogue and critical discussion (the very essence of the public sphere) is often absent on the Net. The article argues that open-access Public Service Media (PSM) are capable of developing more comprehensive and inclusive social frameworks than online providers. As trusted media brands, PSM contribute to the creation of an inclusive public sphere, enhanced civic engagement and informed citizenship.

\section{Media Market Changes}

The mass media model that characterised most of the past century was influenced by structural arrangements based primarily on a market economy and minimum state regulation. This model developed within the control of media proprietors and relied upon monetised labour, and was co-opted by institutional arrangements such as class, race and gender. It was subject to only a modicum of constraint by governmental policy operating within the nationstate system (Picard, 2014: 98). Today, the media landscape is undergoing transformations that change those structural arrangements through the processes of digitalisation, globalisation, and the appearance of increasingly influential actors beside the state, such as intergovernmental agencies, civil society and grass root organisations. These intermediaries give power of speech to people who previously did not have effective means of raising their voice. Civil society includes all those who are not part of government, private enterprise or intergovernmental organizations (Raboy, 2004: 228). Non-state entities such as nongovernmental organizations (NGOs) would be examples of sub-national hierarchies existing 
below the purview of states (Kumar, 2010: 157). Transnational movements of civil society and NGOs have been playing an important role lately in influencing the processes of decision-making in international media and communication policy. UNESCO and other global organizations that represent the non-corporatist perspective on the media gradually gain momentum. This is evidenced by the Convention on Cultural Diversity, which represents a protectionist alternative to the principles of free trade and highlights UNESCO's renewed role into the arena of global media governance.

But it is mainly technological developments that are changing who can communicate, what is communicated, and how it is communicated. Citizen-consumers use contemporary communication technologies for self-expression, participating in self-defined communities, and contributing to debates about developments in society. These technologies represent a shift in democratic responsibility from institutional media to amorphous digital communities and are important to the public as they pursue personhood, identity and culture (Picard, 2014: 99). These online forums or social spaces of the Web 2.0 differ substantially from the traditional ones such as that of Public Service Broadcasting (PSB) in that they allow more interactivity and many-to-many communication, rather than one-to-many. They appear to be ideal spaces for initiating public debate and social change. This issue will be dealt with in the next section, especially with reference to political power, but we first need to provide some definitions and statistics relating to social media in order to put things into context.

\section{The Growth of Social Media}

Social media are defined as 'online resources that people use to share content: video, photos, images, text, ideas, insight, humour, opinion, gossip, news' (Drury, 2008). In other words, they are a blur of tweets, shares and content. They are global and embedded in every corner of the web and used by all age groups. Social media have become a ubiquitous part of everyday life. In 2013, nearly 630 million people logged into Facebook daily, 48 per cent of its 1.3 billion users. Twitter, Google+, Tumblr and Pinterest get more and more activity every day. And it is a fair assumption that most users will have multiple social networks. Here are some striking statistics about the social media (http://www.jeffbullas.com/2014/01/17/20social-media-facts-and-statistics-you-should-know-in-2014/) -

- 72 per cent of all internet users are now active on social media 
- 18-29 year olds have an 89 per cent usage

- The 30-49 bracket sits at 72 per cent

- 60 percent of 50 to 60 year olds are active on social media

- In the 65 plus bracket, 43 per cent are using social media

- Time spent on Facebook per hour spent online differs across countries, but the top three are the USA, Australia and the UK: US citizens are on top at 16 minutes per hour followed by the Australians at 14 minutes and the British at 13 minutes

- 71 per cent of users access social media from a mobile device.

The above demonstrate that the paradigm of social media only being used by the younger generation should be put to rest now. Facebook is still the biggest social medium, but there are signs that by 2016 Google+ may surpass Facebook on 'social sharing' if one considers that it has only been around for less than three years and that it is growing at 33 per cent per annum. Twitter is also now a public company and it is among the fastest growing networks with a 44 per cent growth from 2012-2013 and 215 million monthly active users in 2013. One should also refer to some other important social media channels, including Pinterest, Instagram, Tumblr, Vine, Slideshare and many others. We end this rather brief section with some of the latest figures concerning leading site Facebook’s 1.3 billion users -

- One million web pages are accessed using the 'Login with Facebook' feature

- 23 percent of Facebook users login at least 5 times per day

- 47 per cent of Americans say Facebook is their number 1 influencer of purchases

- 70 per cent of marketers used Facebook to gain new customers.

\section{The Mobilising Power of Social Media}

The Internet and social media make it easier to organise and agitate as people can participate in reality TV votes, or support a petition within the click of a mouse, or even force out undemocratic governments. There have been networked social movements which largely ignored the political elite, distrusted the established media, were not subject to any hierarchy or formal organisation, and rejected any leadership, relying on networked forums for collective debate and social dialogue (Mosco, 2008). This section attempts to shed light on these movements. 
The political power of social media is striking. On 17 January 2001, during the impeachment trial of Philippine President Joseph Estrada, loyalists in the Philippine Congress voted to set aside key evidence against him. Less than two hours after the decision was announced, thousands of people, angry that their corrupt president might not be charged, arranged a protest chiefly by forwarding text messages reading 'Go 2 EDSA. Wear blk'. Over a million people arrived on Epifanio de los Santos Avenue in the next few days, showing the public's ability to coordinate such a massive and rapid response (close to seven million text messages were sent that week). Alarmed by this massive protest, the country's legislators reversed course and allowed the evidence to be presented, eventually sealing Estrada's fate, who fled the country on 20 January 2001 (Shirky, 2011). The event marked the first time that social media had helped to the downfall of a national leader. As noted by (Castells, 2012: 1):

Suddenly dictatorships could be overthrown with bear hands of the people, even if their hands had been bloodied by the sacrifice of the fallen. Financial magicians went from being the objects of public envy to the targets of universal contempt. Politicinas became exposed as corrupt and as liars. Governments were denounced. Media were suspended. Trust vanished.

The Philippine strategy has been adopted several times since. Several networked social movements erupted against the mishandled management of the economic crisis by governments in the US and Europe. Spain's spontaneous grassroots protest movement called Los Indignados - 'the indignant ones' - began with thousands of mainly young Spaniards camping out in Madrid's central square, Puerta del Sol Tunisia in May 2011 and then spread across the country. With similar symbolism, Greece’s ‘outraged’ (aganaktismenoi) occupied Syntagma, the central square of Athens opposite parliament, the area around White Tower in Thessaloniki, and public spaces in other major cities in June 2011, opposing the strict fiscal measures imposed by the IMF, EU and European Central Bank. In the US, the Occupy Wall Street movement, the name given to a protest movement that began in September 2011 in New York's Wall Street financial district, is another example of a cyberspace-driven movement, calling for social and economic equality, and for curbs to the perceived influence of corporations on government - particularly from the financial services sector. But as the networked population was gaining greater access to information, social movements have spread in the Arab world and in most cases were confronted with violence by established 
dictatorships. Tunisia witnessed the first social media-driven protests of the Arab uprisings and the first ousted dictator, President Ben Ali, despite his attempt to censor Facebook in 2008, a move that simply encouraged more Tunisians to join via proxy sites. Elsewhere, the Communist Party lost power in Moldova in April 2009, following public protests coordinated by text message, Facebook, Twitter and LiveJournal after the announcement of preliminary election results, which showed it was winning approximately 50 per cent of the votes in an obviously fraudulent election.

There are, however, many examples of the activists failing, as social movements experience diverse fates, from victory to concessions, to repeated massacres, to civil war. For example, computer-mediated communication have been instrumental in organising many of the 2009 Iranian election protests, but these died out soon in a controlled society. Also, the activists fell in the 'Red Shirt' uprising in Thailand in 2010, where protesters occupying downtown Bangkok were dispersed violently by Thai government. The protests were organised by the National United Front of Democracy Against Dictatorship (known as 'Red-Shirts'), which called for Prime Minister AbhisitVejjajiva to dissolve parliament and hold elections earlier than the end of term elections scheduled in 2012. In Sudan, the Al-Bashir government quickly stifled the planned 2011 protests opposing its autocratic regime and in Bahrain protests calling for reforms of the monarchist government were successfully cracked down. The biggest opposition protests since the collapse of the Soviet Union in 1991, which started in Moscow in 2011 and gathered tens of thousands of people informed and motivated by blogs and social networks, appeared to be a new stage of democratic development in Russia. They were regarded as a new link in the chain of political protests in the world and termed by western media 'Russian Internet revolution protests' or 'Russian web protests', but soon the potential to confront the authorities and demand change did not achieve this promise. In some cases, demonstrations resulted in some welcome reforms such as the lifting of a long-standing state of emergency in Algeria. In other cases, throwing out an autocrat did not result in a viable democratic government. This is what happened in Ukraine's Orange Revolution of 2004 when Viktor Yanukovych was ousted from office by vast street protests organised by social media, only to be re-elected to the presidency in 2010. Following the turmoil in Ukraine to herald a democratic future, in February 2014 Viktor Yanukovych reportedly fled to Russia, pursued by a charge of mass murder. 
The situation in Egypt and elsewhere in the Arab world and Middle East demonstrates that emerging democracies can slip back into misrule without a proper underpinning. The collapse of Hosni Mubarak’s regime in 2011, amid giant protests organised by social media, raised hopes that democracy would spread in Middle East, but the euphoria did not last for long as Egypt's first democratically elected party (Muhammad Morsi's Muslim Brotherhood) attempted to impose a permanent Islamic majority before the army stepped in, arresting him and imprisoning leading members of the Brotherhood. Together with ongoing war in Syria and anarchy in Libya, this has dashed the hope that the Arab spring would result in democracy across the Middle East (The Economist, 2014). Political upheavals in Tunisia, Egypt and Libya show that the governments that replaced authoritarian regimes are yet to prove that they will adopt the liberal democratic values called for by the demonstrators. Moreover, the likelihood of civil war in Yemen and the continued deadly unrest in Syria cannot be ignored. Therefore, social media can certainly mobilise people, but can they also contribute to sustainable democracy and the creation of a public space?

\section{Social Media andDemocracy}

The key question to address here is whether social media contribute to democracy, revolution and expansion of the public sphere, or whether social media are first and foremost instruments of control and commerce (see Iosifidis, 2011a, 2011b). To this end, the work refers briefly to Habermas's concept of the public sphere, which remains a central analytical tool to help us make sense of the relationship between the media and democracy (civic engagement). In his Structural Transformation of the Public Sphere, originally written in 1962, German philosopher and sociologist Habermas explained that in the late eighteenth century a new political class (the bourgeoisie) came to the fore in Britain in particular and formed a public body which, in sharp contrast to the old authorities, notably the state and the church, provided the conditions for reason-based, public opinion. The creation of a network of institutions by the bourgeoisie within the civil society, and the launch of a number of newspapers more specifically, provided the means through which private thoughts could become public. Libraries and universities became the places for public debate, while publishing enterprises formed the means by which government was criticized. Habermas's theory merits consideration because he carefully conceptualised the nature of the public sphere, viewing it as an achievement of the new bourgeois (or capitalist) class in Europe, and an outcome of its successful struggle against feudalism and church or state oppression. 
Although the historical status of Habermas's theory may be questionable - the German scholar has been criticized, first, for idealising the early period of history he referred to and particularly the notion of the 'independent' eighteenth century press, and second, for his rationality argument), he nevertheless pioneered in pointing out that the public sphere - a conceptual rather than physical space - and democracy - expressed through engagement in rational discussion - are closely connected. Habermas' thinking, through the contributions and limitations of his thesis, provides valuable theoretical resources to advance important issues relating to democratic society in the contemporary era. He offered a starting point for understanding the media's role in public communication. Of significance here is the public sphere's potential transformation to a so-called networked public sphere. The aim is to advance the discussion of how the social dimension of the Internet and social movements create a public space for deliberation, which ultimately becomes a political space, 'a space for sovereign assemblies to meet and to recover their rights of representation, which have been captured in political institutions predominantly tailored for the convenience of the dominant interests and values' (Castells, 2012: 11). Put it another way, can traditional 'public service media’ give way to 'public service Internet'?

\section{Social Media: Unstructured Participation}

To answer the above question this section engages with social media sceptics and discusses various concerns that have arisen regarding the contribution of electronic networks to democracy. First, the open participation of the Internet and social media can turn chaotic in which there might be no model rules of behaviour, thereby allowing no structured conversation. Gladwell (2010) stressed that successful activism requires strategic hierarchies, with a careful and precise allocation of tasks. In contrast, social media create loose and essentially leaderless networks, not capable of organising revolutions. As networks typically do not have a centralised leadership structure and clear lines of authority, they cannot reach consensus and cannot set strategic goals. A relevant issue is that social sites also have the tendency to distract people from important issues. Morozov (2012) believes that few people use the Internet and social media for political activism, whereas huge numbers view in there pornography, play games, watch movies, or share pictures. These trivial uses of the Internet and social media are well known in the West and they are now spreading in authoritarian regimes. Furthermore, Morozov notes the danger that the sheer volume of information available through social media - coupled with its increased general availability via the 
Internet and 24/7 news cycles - creates shorter attention spans in which important news is quickly supplanted by new developments elsewhere. For example, the 'Twitterverse' flocked to read and retweet news of the ultimately unsuccessful Iranian uprising of June 2009. Yet the story was swiftly cast aside upon the death of pop megastar Michael Jackson. While social media may create quicker and louder conversations, those conversations may tend to be shallow, short, and easily displaced by the newest 'big thing' (Joseph, 2012).

\section{Unreliable Information}

A related issue is that a good deal of the Internet's content is unreliable. As a widespread source of information the Internet should provide reliable, authentic and up-to-date information, but user generated content and blogs, in particular, are often defined as unreliable sources, containing personal and one-sided opinions. It is fair to say that common sense (house rules) and common decency should be the rule, or acceptable practice, when posting materials on the Internet, but as this is largely a self-regulated area, reaction comes only when someone complains. There is clearly a need for a better balance enforcing appropriate online behaviour, the assignment of liability, and protecting freedom of speech. Frankly providing an informed (and safe) online experience is important both for users and businesses. Dahlberg (2007) has found that the online debate is polarised and there is generally a lack of listening to others. He pointed out that the Internet and social media fail to adequately consider the asymmetries of power through which deliberation and consensus are achieved, the inter-subjective basis of meaning, the centrality of respect for difference in democracy, and the democratic role of 'like-minded' deliberative groups. What is often absent in online deliberations is a consensus-based, justified and rational decision, let alone that not everyone affected by that decision is included. But it is fair to say that very little of online content is legally actionable, and an even smaller proportion is actually subject to any kind of legal action. Exceptions to this are cases like the famous Sally Bercow tweet case that took place in the UK. In November 2012 Bercow used her Twitter account to hint the name of Lord McAlpine, a Conservative peer, alleged by the BBC to be a paedophile. The allegations proved to be unfounded, and the peer took legal action against Bercow and others. In May 2013, the High Court found that Sally Bercow's tweet 'was libelous' and Bercow agreed to pay damages. However, most content that people are publishing is not defamatory. At a European Union level, the eCommerce Directive (EU, 2002) establishes clear rules and protections that online retailers and service providers must comply with when dealing with 
consumers in the member countries of the EU, covering platforms that are allowing other people to publish user generated content.

\section{Censorship}

Third, censorship might be an issue. The extent of Internet censorship varies on a country-tocountry basis. While most democratic countries have moderate Internet censorship, other countries go as far as to limit the access of information such as news and suppress discussion among citizens. In countries like China, North Korea and Cuba the respective governments restrict their citizens' Internet access by blocking specific websites. Amnesty International, a non-governmental organisation dealing with human rights, notes that China has the largest recorded number of imprisoned journalists and cyber-dissidents in the world. Facebook, Twitter and YouTube are all explicitly blocked in China, while in March 2010 Google withdrew from China owing to an ever stronger censorship of its searches. Domestic Chinese equivalents of these sites, such as Baidu, Taobao, Renren and QQ have been launched, that can be more readily controlled by the state. Likewise, the Cuban Internet is among the most tightly controlled in the world, while Internet access in North Korea is only permitted with special authorisation and primarily used for government purposes. In Turkey, on 20 March 2014 the Erdogan government imposed a block on Twitter after tweets began spreading linking the prime minister to a corruption scandal, only to be lifted a few days later thanks to a Turkish court order. Douglas Frantz, an American State Department official, likened the move to ' $21^{\text {st- }}$ century book burning' (see http://blogs.state.gov/stories/2014/03/21/21stcentury-book-burning, accessed 28 March 2014). The United States' history on freedom of expression has not always lived up to the highest values, for post 9/11 brought about privacy and freedom concerns even in a country with a strong democratic tradition such as the US, as evidenced by the passing of the 2001 Patriot Act which expanded law enforcement's surveillance and investigative powers. In Europe, in the immediate aftermath of the British riots in August 2011, which resulted in widespread looting and property damage, British Prime Minister David Cameron partially blamed social media for the unrest, and raised the possibility of banning criminals from and otherwise censoring social networks.

\section{Corporate Online Activity and Privacy Concerns}

Fourth, the Internet has become a major arena for corporate activity, similarly to other brunches of the cultural industries. Individualisation of consumption has been accompanied 
by consolidation of media ownership producing global multimedia corporation intent on redeveloping cyberspace as retail real estate (Murdock 2004). Fuchs (2011a) argues that the Internet and social media are today stratified, non-participatory spaces, and an alternative, non-corporate Internet is required. Giant corporations colonise social media and dominate their attention economy. In a more recent work, Fuchs (2014) takes a step further and contends that big corporate (and to a lesser extent, political) actors dominate and therefore centralise the formation of speech, association, assembly, and opinion on social media.

Liberal freedoms turn on capitalist social media into their opposite. The concept of social media participation is an ideology...it seems both necessary and feasible to theorize "Web 2.0" not as a participatory system, but by employing more negative, critical terms such as class, exploitation and surplus value (ibid: 102).

Corporate social media gather data on users by continuously monitoring and recording online activities. Collected data are then stored, merged and analysed in order to create detailed user profiles containing information about personal interests and online behaviours. This, in turn, enables targeted advertising with the objective of luring consumers to buying products and services. The mechanism of targeted advertising on social media has been termed 'panoptic sorting' (see Gandy, 1993a, 1993b) as social media obtain an accurate picture of the interests and activities of their users. According to Fuchs (2014: 110) corporate social media sell the users' data commodity to advertising clients at a price that is larger than the invested constant and variable capital. Fuchs (2013) argues in another work that social media 'prosumers' are double objects of commodification: they are commodities themselves and through this commodification their consciousness becomes, while online, permanently exposed to commodity logic in the form of advertisements.

With the rise of user-generated content, free access social networking platforms, and other free access platforms that yield profit by online advertisement - a development subsumed under categories such as web 2.0, social software, and social networking sites - the web seems to come close to accumulation strategies employed by the capital on traditional mass media like TV or radio. The users who upload photos, and images, write wall posting and comments, send mail to their contacts, accumulate friends or browse other profiles on Facebook, constitute an audience commodity that 
is sold to advertisers. The difference between the audience commodity on traditional mass media and on the Internet is that, in the latter case, the users are also content producers; there is user-generated content, the users engage in permanent creative activity, communication, community building, and content-production (ibid).

In policy terms, since 2011, advertisements on social media have been covered by the very same rules as other advertisements have been. Policy priorities should perhaps be to ensure that rules are well understood and followed by all interested parties. As the Internet is typically a self-regulated area, what is required is transparency, or making clear that an advertisement is in fact an advertisement. People need to know when they are being advertised and the responsibility to make it obvious lies with the social media sites. The Universal Nations Charter (1945) and the Universal Declaration of Human Rights (1948) established rules and norms that countries could not bridge. Specifically on the issue of how companies are collecting data and the way they are using it, there apply the classic Universal Declaration of Human Rights (Article 12 Right to Privacy) and also the European Convention on Human Rights (Article 8 Right to Privacy), which is a right, effectively, to the privacy of our correspondence. In the UK, the Data Protection Act 1998 defines UK law on the processing of data on identifiable living people and it is the main piece of legislation that governs the protection of personal data in the country. Although the Act itself does not mention privacy, it was enacted to bring UK law into line with the EU data protection directive of 1995 which required Member States to protect people's fundamental rights and freedoms and in particular their right to privacy with respect to the processing of personal data. In practice it provides a way for individuals to control information about themselves.

There is a big debate concerning the privacy of peoples' correspondence when using online services such as email, text messaging and social media. Put it simply, people in the past created some content with the expectation that that content should remain private, but with the advent of social media this is now in the public space, with text messages and tweets. Once we are onto Facebook or Twitter we are basically telling everyone where we are, what we are doing, 27 hours a day. This social media world creates an environment of open distribution and as the technology is indeed pervasive and the amount of data we are creating very large, it makes it difficult to regulate. But do large social media sites take steps to protect user privacy? Perhaps we should refer to Christian Fuchs' critical discourse analysis 
of Facebook’s privacy policy (2011b) in order to draw a conclusion on how social media treat privacy issues. In what Fuchs called liberal or bourgeois notions of privacy (Fuchs 2011b), he contends that such notion of privacy masks socio-economic inequality and protects capital and the rich from public accountability (Fuchs 2011b: 140). Fuchs shows the asymmetric relationship between social media providers and social media users and argues that social media sites like Facebook frame privacy in a way that protects their interests at the expense of their users. His findings are echoed by other critical discourse studies which also demonstrate the continued commodification of user data by Facebook and Twitter (see Butosi, 2012).

\section{Absence of Critical Discussion}

Fifth, extensive dialogue and critical discussion (the very essence of the public sphere) is often absent on the Net. There seems to be a gap between 'access to information' and 'ability to conversation and dialogue' as meaningful debate is typically absent in social networking sites, which are dominated by trivial communication. In the case of the Twitter, for example, dialogue is limited by the very fact that it only allows the exchange of swift, short messages (up to 140 characters). This implies that there might be an increase in the number of active participants in the communication process, albeit leaving little space for substantive social and political dialogue involving groups and individuals. Shirky (2011) argues that 'political freedom has to be accompanied by a civil society literate enough and densely connected enough to discuss the issues presented to the public'. He endorses the theory of sociologists Elihu Katz and Paul Lazarsfeld (1970) that the formation of well-considered political opinions is a two-step process. The first step requires access to information; the second, use of that information in conversation and debate. Under this framework, Shirky argues that social media sites have revolutionised how people form political opinions and have made information so widely accessible that more people than ever are able to develop considered points of view.

Lastly, despite its increasing prominence as a place where people access news and advertisers spend money, the Internet remains a distribution medium, not a source of original news content. Although Internet companies invest in this medium, the investment has tended to be in technology and not in journalists. Internet sites unaffiliated with traditional media typically 
collect stories from various newspapers and wire services, or comment on the news, but do little original local news coverage or investigative reporting.

So, is it just a myth that the Internet has the ability to contribute to democracy by creating a healthier public sphere? Is the creation of new social and political units by social media a cyber-fantasy? Not quite. If traditional media like newspapers helped to set up public spaces where people initiated forms of communication within nation-states, new social media can do likewise in the international space in which citizens increasingly invest their time to communicate with each other and create things. Lessig (2006) predicted that online communities would transcend the boundaries of conventional states and this is true if one thinks of Facebook with its 1.3 billion users. The Economist (2010) writes that Facebook is unprecedented not only in its scale but also in its ability to blur boundaries between the real and virtual worlds. From the users' viewpoint, the social network can be seen as a liberal polity: a space in which people air opinions, rally support and right wrongs (The Economist 2010). Viewed this way, Facebook can make the world more open and connected, more like a 'global village' forecasted in the 1960s by futurologist McLuhan. However, it all depends on how one uses the Internet and social media. We should not forget that the Internet, as all new media technologies, can provide a useful tool or the basis for a healthier democracy and an enhanced public space, but they cannot themselves create such a space. To cite Kellner (1997) the Internet - as all new media technologies - can either be used as instrument of empowerment or domination.

\section{Public Service Media and Democracy}

The above issues make one reconsider the role of public access media in enhancing civic engagement, forming political identities and culture, and tackling the 'democratic deficit' in the era of commodification of the communications media. In the USA, public access television has been for some decades now an established venue for alternative democratic communication. In Europe, Public Service Broadcasting has traditionally been open to all at affordable prices - usually households are required to pay an annual licence fee in exchange for high-quality content, especially in news, current affairs, education and the dissemination of culture. Of course, these media are top-down hierarchical institutions and as Kellner (1997) admits, many will claim that democratic politics involves face-to-face conversation, discussion, and producing consensus. But for intelligent debate and consensus to be reached, 
individuals must be informed and public service media, accessible to all, are important sources of information in the present age, helping activist groups and individuals obtain and disseminate information. Apart from being universally accessible, public service media has proved a credible and trustworthy source of information. During the second Gulf war and more recently in the Russia-Ukraine crisis, more people tuned to the BBC and its unrivalled team of correspondents in accessing news and reaction. Also the websites of public service media rank among the most visited non-commercial portal sites, with the BBC being the most trusted and widely used site in Europe (Council of Europe, 2008: 14). It has achieved this position by exploring ways the Internet can extend public broadcasting's core mission of offering cultural resources for thick citizenship (Murdock, 2004). And although the Jimmy Savile scandal in the UK challenged the link between trust and accountability (in 2013 the BBC was reeling from revelations about how one of its longest-serving and best-known presenters, the late Jimmy Savile, had systematically used his fame to obtain access to children whom he sexually abused), the shared commitment of public service media to the public interest and to the common good is well established.

True, PSM face many challenges, including the pressures generated by rapid technological change; the dilemma between the obligation to safeguard citizenship ambitions and support market principles; and the legitimacy and performance of public media in a multimedia ecology characterised by convergence and fragmentation. Technological change and growing competition in broadcasting has opened up media markets and enhanced media choice, challenging thus the performance of publicly funded institutions. Furthermore, the shape of society and the mass media have become more internationally-oriented and this shift has brought into question the very legitimacy of national communities, identities and ideologies. In the light of the above changes PSM are struggling to come to terms with Europeanisation and globalisation of media ownership, production, programming and distribution, the 'marketisation' of media output, technological convergence and audience fragmentation. While the prevailing nation-state frameworks for cultural and political identity are gradually fading, some PSM are finding it hard to serve and promote national culture and identity, and meet the challenges of the growing uncertainties in light of a globalisation. But as has been argued elsewhere (Lowe, 2007; Iosifidis, 2010) these are considered among the central institutions that can help citizens make sense of such developments by bearing traces of collective identities and therefore creating an expanded social and cultural space. 
Public service media can make a socio-cultural difference and contribute to the creation of an inclusive public sphere and enhanced civic engagement in at least three broad areas: information (particularly factuality and accuracy of news and public representations); cultural representation (which creates a pluralistic social and cultural community); and universality (as PSM are available to all at the point of reception). PSM offer a counterbalance to commodification of media and concentration of power to established (Disney, News Corp, etc.) but also new media titans (Facebook, Google, Amazon, etc.). PSM functions and the value it provides are not offered in equal volume and quality by online content providers and profit-driven systems. Universal coverage and widespread access of PSM guarantee a public space reached by mass audiences which can function as a forum for democratic public discourse. An important characteristic of the civic role related to the public sphere is the availability of impartial, accurate, non-market oriented news and current affairs that are provided by public media. Another is the provision of high-quality (innovative, risky, diverse and home-grown) programming and culture for various minority ethnic and religious groups in a pluralist, multi-cultural society. These socially beneficial PSM functions imply that public media should be maintained in today’s deregulated communications marketplace. There is a continued need for strong, well-funded public institutions, capable of delivering socially valuable content that would keep public debate alive. But for this to happen, regulation should ensure, first, that PSM have the necessary mandate as a core component of their remit, and second, that PSM are held to account for fulfilling its mandate and mission. As Council of Europe (2008) noted, policy needs to recognise the role of PSM as one of the priorities in democracy for citizens to ensure their sufficiency in both resource and support.

\section{Conclusion}

This article provided a political economy analysis, with a focus on market and regulatory issues, to understand the implications of social media for power structures in society. To summarise the main arguments: whereas some hold that social media make the economy more democratic and that Internet social movements have been used as tools of revolutions and democratisation ('revolution 2.0; Facebook/Twitter revolution'), others say that social media are instruments of control and commerce. Evgeny Morozov is a leading voice of the so-called cyber-sceptic school of Internet studies, for his 2012 book The Net Delusion chronicles and explores in much depth the inflated hopes invested by the West in the Internet. Morozov argues that the initial democratising potential of the Web has been challenged by 
the very presence of authoritarian governments which have developed their own presence on the Web, to powerful effect. He deploys a number of examples to demonstrate that antidemocratic forces increasingly manipulate the Internet, such as the Chinese government's decision simply to turn off the Internet for ten months in 2009 amid the growing unrest in Xinjiang. More recently, in March 2014 the Turkish government banned Twitter, after users shared information about allegations of corruption against high-profile officials. Equally problematic is the use of the term revolution in the context of the Arab Spring. Kandil (2011) has stressed the powerful role of social media in revolutionising movements in Egypt and elsewhere as people utilised them as an effective means to spread information, yet he argued that it is important not to overemphasise the role of technology and underestimate the historical, material conditions that led up to such political upheaval. This view is echoed by Gladwell and Shirky (2011) and Joseph (2012) who remain sceptical with regard to the information and conversation element of the social media despite their apparent contributions to the seismic events of the Arab Spring in terms of progressive social activism.

This article shares the concerns of the cyber-sceptics regarding the democratic value of social networks and argues that while social media can certainly mobilise people they fall short in creating and sustaining a public space devoted to constructive and informed debate. Political and economic power which has traditionally been tied with established media is being diverted to online social networks. These are much cheaper to create and expand, and therefore much more accessible for most people. The new ways of communicating offer a higher interactivity and a higher connectivity, both essential to the development of the public space. But the rise of social media has been associated with concentration of power, corporatism and commercialism, censorship, electronic surveillance, data protection and privacy concerns. Above all, there seems to be a gap between social media's ability to mobilise people and their ability to initiate and maintain meaningful debate and dialogue. Given these online movements are new it might be too early to evaluate their ultimate contribution to democracy and cultural change. However, commercialisation and the digital revolution have made some of democracy's most cherished institutions look more relevant than ever: strong, accountable and independent public service media can serve the public interest and the common good by enhancing public deliberation. 


\section{References}

Butosi, C. (2012) 'Social Net-Working: Exploring the Political Economy of the Online Social Network Industry', Thesis submitted in partial fulfilment of the requirements for the degree of Master of Arts, Western University. http://ir.lib.uwo.ca/cgi/viewcontent.cgi?article=1692\&context=etd (accessed 26 March 2014).

Castells, M. (2012) Networks of Outrage and Hope: Social Movements in the Internet Age. Cambridge: Polity.

Dahlberg, L. (2007) 'Rethinking the Fragmentation of the Cyberpublic: From Consensus to Contestation’, New Media and Society 9(5): 827-47.

The Economist (2010) ‘The Growth of the State: Leviathan Stirs Again’, 23 January, pp. 2224. The Economist (2014) 'Essay: Democracy’, 1 March.

European Union (EU) (2002) The Electronic Commerce Directive (00/31/EC) and The Electronic Commerce (EC Directive) Regulations 2002 (SI 2002 No. 2013).

Fuchs, C. (2011a) Foundations of Critical Media and Information Studies. New York: Routledge.

Fuchs, C. (2011b) 'An Alternative View of Privacy on Facebook', Information 2(1) (February): 140-65.

Fuchs, C. (2013) 'Social Media and Capitalism: In Producing the Internet' in Critical Perspectives of Social Media, T. Olsson (ed.), 25-44. Göteborg: Nordicom.

Fuchs, C. (2014) Social Media: A Critical Introduction. London: sage.

Gandy, O.H. (1993a) ‘Toward a Political Economy of Personal Information’, Critical Studies in Mass Communication, 10(1): 70-97.

Gandy, O.H. (1993b) The Panoptic Sort. Boulder: Westview Press.

Gladwell, M. (2010) 'Small Change’, New Yorker, 4 October http://www.newyorker.com/reporting/2010/10/04/101004fa_fact_gladwell (accessed 22.3.14).

Habermas, J. (1962) Structural Transformation of the Public Sphere.

Iosifidis, P. (2010) Reinventing Public Service Communication: European Broadcasters and Beyond. Basingstoke: Palgrave Macmillan.

Iosifidis, P. (2011a) Global Media and Communication Policy. Basingstoke: Palgrave Macmillan. 
Iosifidis, P. (2011b) ‘The Public Sphere, Social Networks and Public Service Media’ Information, Communication \& Society 14(5): 619-37.

Joseph, S. (2012) 'Social Media, Political Change, and Human Rights’, Boston College International and Comparative Law Review, 35(1): 145-88

http://lawdigitalcommons.bc.edu/iclr/vol35/iss1/3 (accessed 25.2.14).

Katz, E. and Paul F. Lazarsfeld (1970) Personal Influence: The Part Played by People in the Flow of Mass Communications. Transaction Publishers.

Kellner, D. (1997) 'Intellectuals, the New Public Spheres, and Techno-politics’ http://www.gseis.ucla.edu/faculty/kellner/essays/intellectualsnewpublicspheres.pdf (accessed 27 March 2014).

Kumar, S. (2010) 'Google Earth and the Nation State: Sovereignty in the Age of New Media’, Global Media and Communication 6(2): 154-76.

Lowe, G.F. (2007) The Role of Public Service Media for Widening Individual Participation in European Democracy (Strasburg: Council of Europe), November.

Mosco, V. (2008) Current Trends in the Political Economy of Communication' Global Media Journal- Canadian Edition 1(1): 45-63.

Picard, R.G. (2014) 'Panel I: The Future of the Political Economy of Press Freedom', Communication Law and Policy, 19(1): 97-107.

Raboy, M. (2004) 'The World Summit on the Information Society and its Legacy for Global Governance', International Communication Gazette 66(3-4): 225-32.

Shirky, C. (2011) 'The Political Power of Social Media: Technology, the Public Sphere, and Political Change', Foreign Affairs, January/February issue http://www.foreignaffairs.com/articles/67038/clay-shirky/the-political-power-ofsocial-media (accessed 21.3.14). 